\title{
The landing obligation calls for a more flexible technical gear regulation in EU waters - Greater industry involvement could support development of gear modifications
}

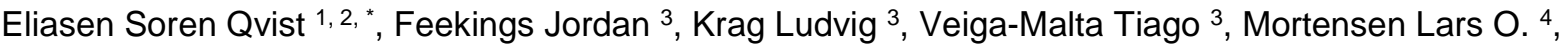 \\ Ulrich Clara ${ }^{5}$
}

${ }^{1}$ Aalborg Univ, IFM, A C Meyers Vaenge 15, DK-2450 Copenhagen SV, Denmark.

2 NordRegio, Holmadmiralens Vag 10, Stockholm, Sweden.

3 Tech Univ Denmark, Natl Inst Aquat Resources, Hirtshals, Denmark.

4 DHI, Horsholm, Denmark.

5 Tech Univ Denmark, Natl Inst Aquat Resources, Lyngby, Denmark.

* Corresponding author : Soren Qvist Eliasen, email address : se@plan.aau.dk

\begin{abstract}
:
Rigid fisheries management frameworks often leave fishers with limited possibilities and incentives to adjust the selectivity of their gears to the specific fishing conditions. Implementation of the landing obligation in European fisheries emphasizes fishers need to flexibility in which gear to use to be able to match the selectivity of the gear to the quota available. How fishers can play an important role in facilitating a more regionalised and flexible technical regulation by actively participating in the development of gears and contributing to the scientific documentation of their selectivity is discussed. Perspectives in the proposed technical regulation for EU fisheries and the regionalisation in the 2013 Common Fisheries Policy are discussed based on an analysis of the current EU technical regulation. Then is discussed a new pathway to address the problem, currently being trialled in Danish fisheries. Throughout the article, three themes are discussed: Identifying gear needs, development and testing of gear with fishers as central actors; how the selectivity of the gear should be documented; and opportunities for faster evaluation of new gear, following the regionalisation of the technical measure regulation. The paper concludes that a more flexible system of gear development and evaluation is possible by a) involvement of fishers in proposing gear adjustments, self-sampling and documenting results following scientific protocols and evaluation, testing a range of designs before scientific testing, and b) open for faster approval of gear use under a regionalised technical regulation regime with yearly adjustments of management plans containing the technical regulation.
\end{abstract}




\section{Highlights}

- The landing obligation requires the fishers to have gear flexibility to match the selectivity of gear to the available quota. Regionalisation of management plans opens for faster evaluation and decision on proposed new selective gear variations. Scientific support to fishers ideas speed up identification of promising gear design for scientific tests at a low-cost. - Fishers involvement depend on processes for gear development and political implementation of successful selective gears. The debated EU Technical measures regulation might prove gear flexibility and fast tracking processes and fisher involving.

Keywords : Landing obligation, Gear development, Fisher involvement and engagement, Technical measure regulation in EU, Regionalisation 


\section{Introduction}

\subsection{The stage: mismatch of catching capacity and landing opportunities}

In the European Union (EU), fisheries management is handled at a European level, where political decisions are typically enacted through the Common Fisheries Policy (CFP). The main objective of the CFP is to ensure that the fish stocks are maintained or brought to a sustainable level [1]. Political decisions concerning fisheries management within the EU are typically enacted for an entire region, with little option to account for the complex differences which occur across and within the fisheries. This is also the case for the specification of fishing gears, where only one or few gears have typically been prescribed for each fishery and region [2]. Furthermore, to enforce the regulation and ensure compliance, detailed technical regulations and control mechanisms are established. Conversely, the fishing sector operates mainly with a short-term perspective oriented towards maximising or sustaining revenues. Despite the industry's main focus being on short-term economic interests, conserving the fish stocks for future generations is also of importance for the fishing industry. This aspect has become more important to the industry with the introduction of Individual Transferable Quotas (ITQs) and long-term management plans.

Another difference between the two perspectives is that the available quotas, quota combinations and detailed technical regulations do not necessarily reflect the actual species composition encountered and caught by the fishers on a day-to-day basis. The technical regulation has focused on an overall best solution for each region, while fishers face a much more complex reality, where the specific location, time of day or year, weather conditions, vessel configuration, quota combination etc. all form the framework for planning and conducting the specific fishery. Furthermore, a one-solution-fits-all technical regulation provides little possibility for fishers to adjust the selectivity of their gears to suit the quotas that are available to them.

The traditional way fishers have adjusted their catches to the available quotas has been to discard part of the catch, a practice which is being phased out in the EU as part of the CFP reform [1]. The practice of discarding has typically been the most cost-efficient approach, as there has previously been no direct or indirect costs associated with it. In contrast, changing the selectivity of their gears so that catches would suit the available quotas would often result in a loss of income, which is exacerbated by the limited flexibility in the gears that can be used in the current technical regulation [3],[2]. Therefore, development and testing of selective gears has been limited, and the voluntary uptake of selective fishing gears has remained almost non-existent.

\subsection{The issue: changing policy framework with the landing obligation}

In the latest revision of the CFP, a landing obligation was introduced and gradually implemented from 2016 to 2019. All catches of listed regulated species are gradually supposed to be landed and counted against the quotas, regardless of whether the fish are under or over the Minimum Conservation Reference Size (MCRS) [1]. If enforced, the landing obligation creates an economic incentive for fishers to avoid catching what has traditionally been discarded, and thus to become more selective in their fishing practices.

Adjusting catch compositions to the available quotas can be achieved in two ways. Firstly, fishers can use their experiences and knowledge, either individual [4] or collective [5],[6], to avoid areas and times where catch compositions (species and sizes) do not match the desired catch profile. This is something which is only partly regulated in the technical regulation through permanent and temporary closures, and is 
therefore typically addressed through individual and collective behaviours. Secondly, fishers can adjust the selectivity of their fishing gear to better match the available quotas. The technical specifications of fishing gears is something which is much more detailed in the present technical regulation [3]. Despite it being possible to make some modifications within the specifications of the regulation, it is a difficult and lengthy process to get authorisation for using a gear not specified in the regulation. If a fisher wants to modify a gear out of line with the technical regulation, the modified gear's selectivity has to be scientifically documented. Such documentation requires extensive scientific trials, which are expensive and time consuming, and the subsequent process of getting approval for legal use is complex. This in itself has limited the fisher's interest in participating in such gear development. In this way, the technical regulation, which has been developed to ensure a desired level of selectivity, might be a barrier for fishers to adjust the selectivity of their gears to optimise catches and economy under the landing obligation.

\subsection{Overview of key bottlenecks discussed in this article}

The objectives of this paper are to present the issues with the way fishing gears are presently developed, the problems of the current technical regulation under the new management framework, and finally to highlight the need for greater flexibility in the legislated gears. This is discussed in the context of the current gear development process (section 2) and the current technical regulation [3] (section 3). Section 4 presents a possible pathway to develop and scientifically evaluate the selectivity of fishing gears, which is currently being trialled in Denmark. Section 5 discuss perspectives of a proposal for a new technical regulation of the EU fisheries, presently under revision [7],[8]. Finally, section 6 identifies opportunities for increased flexibility in the choice of gears and how such a system could be implemented. Throughout the paper three key bottlenecks are addressed:

- How should gears be developed and tested, as well as the role of stakeholders in this process?

- How should the selectivity of the gears be documented?

- The procedures for deciding on which gear can be used; specifically if the regional groups of national fisheries directors, a central element in the regionalisation of the CFP (e.g. the Baltic BALTFISH high level group and the North Sea Scheveningen Group), can be the nexus for future implementation of the technical regulations in the context of regional management plans?

\subsection{Methodology}

The research is based on desk research mainly of EU and STECF documents as well as research articles. In the process of analysis and interpretation, some elements of the analysed documents have been discussed with key informants around the relevant institutions, e.g. STECF, the EU Commission and the Danish Ministry. The interpretations are those of the authors.

2. The gear development process

Initiation of the gear development process can be from different stakeholders. For several years, management has often been the initiator based on identified problems, e.g. high bycatch of a certain species or size. In these cases, financing for scientific testing has generally followed the initiated gear development process. Initiation from fishers based on experience and identification of specific needs also 
occurs, but the time and effort spent obtaining financing and approval for testing the modification is typically a limiting factor. For scientists, approval for testing fishing gear modifications is usually not a problem; however, financing can be time consuming. The actual process of developing fishing gears commonly follows a method where one aspect of the gear is altered to improve either the selectivity between species or the size selectivity of a particular species. Such modifications are typically scientifically tested on board either commercial (e.g. [2]) or research vessels (e.g. [9]) and the results are published in reports or scientific literature. However, collaboration with industry in all facets of the development process does not ensure that the modifications, when and if adopted, are not negated [2]. Furthermore, due to the high costs associated with carrying out gear selectivity trials, the development phase is typically limited, where only a few gear designs are tested and documented but further continued practical test and development is typically either limited or lacking. Therefore, further adjustments to improve its performance typically do not take place.

The development and testing process is a rather lengthy process, which can take several years after the idea is conceived until the results are obtained and presented to the relevant authorities for possible inclusion in the technical regulations. This is especially the case when the process is initiated from either fishers or scientists, where financing and approval needs to be applied for and obtained before carrying out the trial. Then the gear needs to be constructed, a vessel chartered to carry out the trial, results analysed, report compiled, and finally, if the gear is to be implemented in the fishery, apply to the relevant authorities, as described in section 3 .

3 The current technical gear regulation

\subsection{The content and process of changes}

The current EU technical regulation is a patchwork of amendments and appendixes upon Council Regulation (EC) No. 850/98 [10] . These have been introduced over time, typically addressing specific conservation issues in certain regional seas. The technical measures include spatial and temporal closures to protect fish and habitats and the regulation of minimum landing sizes of fish to be landed commercially, which was converted to Minimum Conservation Reference Size (MCRS) with the revision of the Common Fisheries Policy in 2013 [1]. However, the central elements in the regulation are those pertaining to the operation and design specifications of fishing gears. The technical regulation defines which gears can be used by certain fleet segments, defined by gear type, fishing area and target species. The technical regulation is quite detailed. For some areas and fleet segments, the regulation is very detailed with regards to e.g. the size, shape, number and twine thickness of meshes, the use, placement, joining rate and size of escape panels, or even the type of knots to be used [3, p 12 - article 7, 2d]. The gear specifications intend to secure a certain level of selectivity of the gears used. The gear types to be used within each management area depend on the target species. This leaves one or few fishing gears for fishers to use in each fishery despite large variations in fishing conditions, catch compositions in the specific areas, as well as differences between the vessels in size, equipment, and quota combination.

The procedures for validating and implementing new gears in EU waters are not clearly formalised. However, article 47 and 46 in the regulation [10] provide some guidelines. According to article 47, the Commission should send a proposal for revision and amendments of the 1998 regulation to the Council for decision within three years. Until 2015, the procedures for making the Commission proposals were not 
specified, nor timetable for further revision. The 2013 CFP [1] has changed this, as will be elaborated later. Article 46 in the regulation [10]) specifies that member states can "take measures for conservation and management of stocks" for own flagged fishers and vessels, e.g. further steps than described in the regulation. In this case, the commission shall be informed prior and can require documentation for "all particulars necessary to assess whether their national technical measures comply with (the regulation)" (art 46, litra 3). The regulation does not describe this documentation process, but in general, the Commission can ask the Scientific, Technical and Economic Committee for Fisheries (STECF) to assess the quality of the documentation provided by the member state. The regulation thus specifies that changes can originate from the Commission or member states proposing measures (including new gear), that impose further constrains in the fishing opportunities for its own fishers. The requirements for documentation are not clear, nor are the specific procedures. The acceptance process has changed from 1998, where the procedure for acceptance of changes took place between the EU Commission and the EU Council. Since 2009, decisions came under co-decision between the European Commission, Parliament and Council, following the Lisbon Treaty, while the Commission could decide based on delegated acts following the 2013 CFP [1].

New fishing gear designs have been introduced over time and included in the amendments of the technical regulation. These introductions have been based on ad hoc processes, which in general have been time consuming and expensive because of scientific and political processes. The regulation does not specify the exact process for approval of new gear designs. A flow diagram describing the approval process (Figure 1) has been developed based on Eliasen et al. [11], a study of specific ad hoc processes, and personal communication with knowledgeable administrators at the Danish Agri-fish Agency and DG Mare. The flow diagram outlines the main elements pertaining to the implementation and approval of new fishing gears under the current technical measures regulation.

Figure 1: Flow diagram describing the main elements used for the evaluation and implementation of new fishing gears under the current technical regulation. 

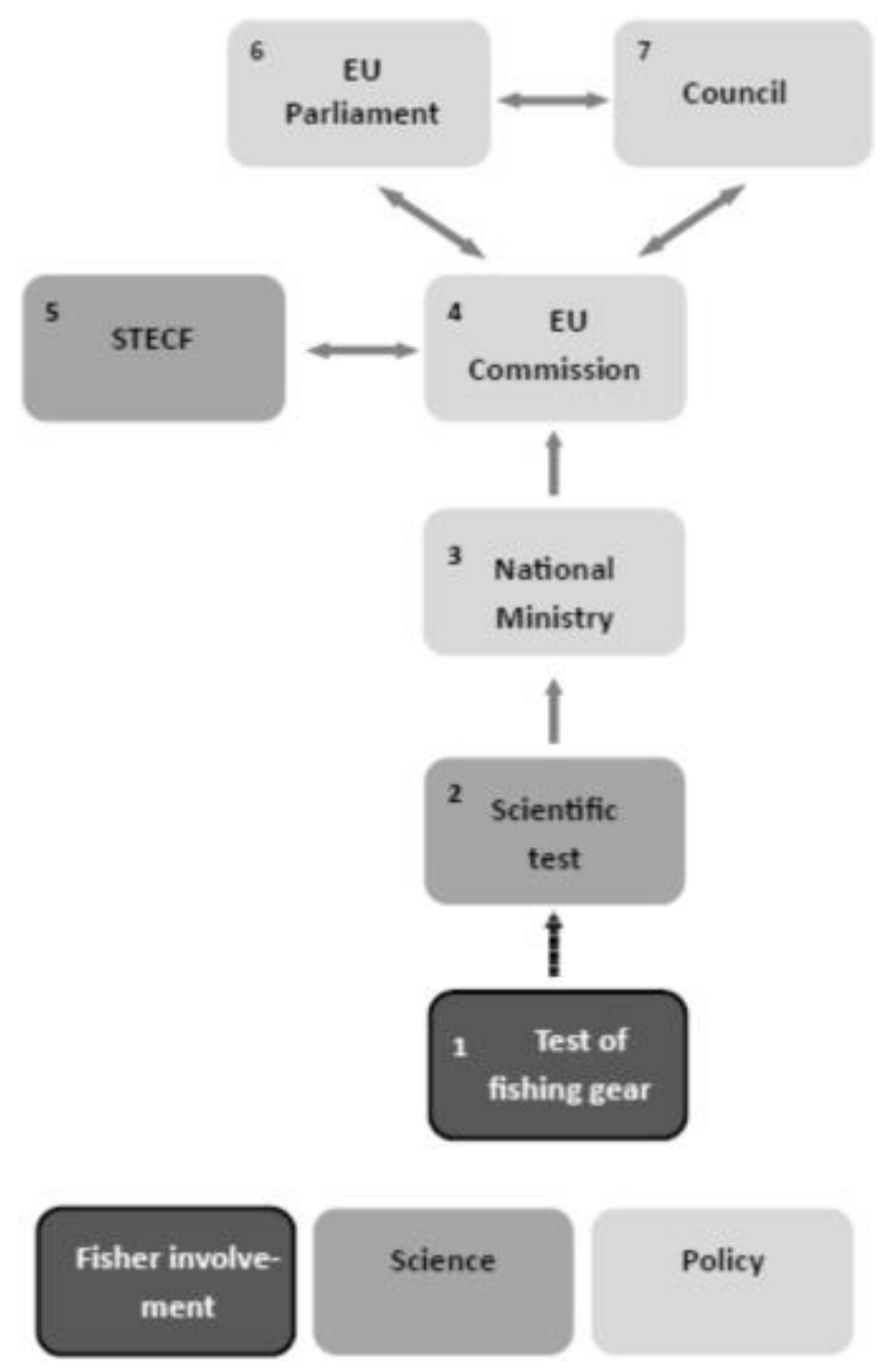

The development of fishing gears is often initiated top-down by management based on a need to increase selectivity, but sometimes initiated by the industry (fishers, trawl makers etc.) or scientists (1). If an idea for a new gear or modification is put forward and falls outside of the specifications described in the technical regulation, it has to be scientifically tested and documented (2) before it can legally be used in the fishery. If the new fishing gear or modification is found to achieve its objective (e.g. reduce unwanted catches), the national authorities (3) can request the EU commission (4) to accept the use of the gear. The EU commission will generally send a request to STECF (5) which provides the EU Commission with a scientific evaluation regarding the documentation and performance of the proposed gear. If the evaluation is positive, the further procedure until recently was that the Commission could make an amendment, which according to the Lisbon treaty has to be agreed on in a co-decision process between the EU-Commission (4), the Parliament (6) and the Council (7) for use in EU waters. The co-decision process in itself tended to be time consuming, at best 6-8 months but typically considerably longer [12] (and personal communication former seconded national expert at the EU Commission, Dominic Rihan). As mentioned, this last procedure has changed due to the 2013 CFP (will be elaborated below). 


\subsection{The role of documentation in the process e.g. STECF role}

As demonstrated in figure 1, gear modifications are typically evaluated by STECF on request from the EU Commission and if approved, the gears characteristics are described in an amendment to the technical measure regulation. An analysis of STECF plenary reports 2011-2015 [13],[14],[15],[16],[17],[18],[19],[20], [21] shows that STECF have been requested to evaluate several gear modifications, including the methodology on request from the EU Commission. In this period, most of the proposals related to selective gear modifications pertaining to the different cod recovery plans, or experiments related to the reduction of discards of whiting and haddock in the Irish and Celtic Seas. The analysis revealed that STECF does not have a formal framework for evaluating experimental results and methodologies, and no formal requirement regarding the type of data to be submitted. STECF proceed in an ad-hoc way based on experts' discussions and built its own experience on the way. As such, STECF show a tendency to require increasing amount of information over time, where requests have been made for additional documentation, alternative statistical analyses and more detailed descriptions of the gear in order to perform a thorough evaluation. For example, STECF required multiple evaluations of the same gear and requested access to haul-by-haul raw data to perform its own selectivity analysis [15],[17],[18],[19]. While the majority of gear trials evaluated consisted of catch comparison trials, there were a few cases where commercial trips with observers were accepted as part of the documentation.

\subsection{Main concerns regarding the technical measures regulations}

The technical regulation, consisting of multiple amendments, each pertaining to specific species and regions has been criticised over the years. A revision was proposed in 2008 , but failed to reach a political agreement [22]. In the process of the 2013 revision of the Common Fisheries Policy (CFP), an evaluation of the technical regulation was undertaken and several alternatives proposed (e.g. [23]). The EU commission established a consultation for input regarding a new framework for technical measures following the revised CFP [24] and a retrospective evaluation of the technical measures [22]. This led to critique, which was summarised in the explanatory memorandum introducing the proposal of a new technical regulation in five bullet points; sub-optimal performance, difficult to measure the effectiveness, prescriptive and complex rules, lack of flexibility and insufficient involvement of key stakeholders in the decision-making process.

The problems are interconnected as mentioned in the MRAG evaluation, stating that the regulation has proven not to be effective at preventing catches of juveniles and unwanted fish, partly because of a "lack of relevance of the design of the intervention which cannot take into account local specificities in a proportional manner" [22, p 3, executive summary]. The prescriptive and complex rules are criticised for imposing high administrative burdens on stakeholders and undermine the fisheries sectors' confidence in the rules, which is reinforced by insufficient involvement in the decision-making process. Finally, the lack of flexibility is described by a "complex, inflexible and lengthy politically-driven process" for decision of technical measures, restricting the "ability to adjust or revise the technical measure to react to changes in fisheries or to take advantage of innovation in gear technology." [8, p. 4]. 
Some of the problems described above regarding the ways gears are developed, tested and subsequently introduced into the current technical regulation are being addressed as part of an ongoing large-scale Danish Fisheries-Science partnership project, FastTrack (www.fast-track.dk). The main objectives of the FastTrack project are to facilitate greater stakeholder involvement in the development and testing of new and modified gears, which can facilitate a greater flexibility in the technical regulations while also streamlining the development process. The project also addresses the management challenges faced in relation to legalising alternative gears.

The FastTrack project offers the opportunity for stakeholders (fishers, net makers etc.) to develop and test their own ideas, in collaboration with scientist, pertaining to new or modified gears in a relatively quick process, while ensuring that adequate documentation is collected for its validation afterwards. An important element of the project is that the project panel (scientists and fisher representatives) is trusted the competence to decide which development to be supported and possible later scientific tested without further application for funding. Often considerable time is spent on writing applications for gear tests. This set-up ensures that development can start immediately after the panel's acceptance, maintaining the momentum, relevance and willingness for the fisher to continue the investment of time and risk of loss of catch by completing the development process.

Two aspects are investigated in the project. The first part focuses on how new and modified gears can be developed and tested, and how stakeholders are involved in the process - boxes 1 and 2 in figure 1 . The second part focuses on the legislative processes around the approval of gears and the potential for a more flexible and adaptive system which can expedite the approval process, boxes 3- 7 in figure 1.

\subsection{Gear development and testing}

The first phase of the development and testing process encourages stakeholders to define their own problems and formulate potential solutions in the form of new or modified gears that they consider will better suit their specific fishery and quota combination. A fisher can either define the ideas himself or get support from other stakeholders (e.g. net makers, consultants at the Danish Fishermen's Producers Organisation (DFPO), or gear technologists at DTU Aqua). The idea is then presented to an evaluating committee, consisting of represents from the DFPO and gear technologists at DTU Aqua. The committee assesses the idea based on two criteria; expected effect (is the idea expected to achieve its objective, e.g. reduce bycatches?) and relevance (is the idea relevant to a wider audience, e.g. does the solution address a problem that could be relevant to other fishers?). If the idea is expected to fulfil the criteria, the project pays a minor sum for the modification of the gear or the new selective devices added to the gear, and requests dispensation from the authorities so that the fisher is able to trial the gear for a limited period. The development and testing period provides fishers with the possibility to resolve some of the technical problems typically encountered when developing and testing new gears, thus overcoming the time and resources limitations frequently occurring when selective gears are typically developed. When the fisher is satisfied with the gears performance, he is required to collect data on the catch. This is typically done in a catch comparison setup [25], where one trawl is the standard gear and the other the modified gear. Both gears are fished simultaneously and in parallel during each haul. A catch subsample from each of the gears is taken and length measured to evaluate the relative catch efficiency of the new gear. The catch comparison analysis is conducted by assessing the rate of experimental catches in the test codend relative to the standard codend. This relatively low-cost self-sampling method ensures that the objectives are met 
before carrying out a full scientific trial to collect the data required by the necessary authorities to have it considered for inclusion in the regulation. Furthermore, such involvement by stakeholders ensures that they are an integral part of the development and testing process, something that is specified in the proposed technical regulations reform [7].

The second phase of the process is a full scientific test under standard scientific methods by DTU Aqua. This phase is also carried out following the catch comparison methodology. The main differences from the industry-led testing phase is that the entire catch of species of concern (e.g. the target species and the main bycatch species) is typically length measured, and the design parameters, which are modified in the new or modified gear, are also tested independently to dissociate the effect of each of the parameters (e.g.[26]). If the scientific test confirms the promising results observed in the industry collected data, the results are presented to the national authorities in order to push for a fast approval process at a national and EU level.

The idea of the project is thus to help facilitate the landing obligation and the proposed reform of the technical measures regulation by providing the necessary flexibility required to be able to fish the quotas available. It also provides a framework for the industry to be an integral part in the development and testing process, while ensuring the data collected are of a sufficient quality to have successful gears passed into legislation. Furthermore, the framework allows sufficient time to fully develop and commercially test the ideas, and an evaluation procedure that is cost efficient. The project thus provides opportunities for a high number of ideas from the industry to be tested in parallel within a short time span.

\subsection{Gear validation and acceptance}

Having the successful ideas implemented into legislation requires them to be accepted by the relevant national and EU authorities. This is linked to the political processes described above. The project also aims to promote the use of the developed gear modifications, on the premise that it fishes as selective or better than those currently legislated. The administrative and political processes were thus further assessed in order to propose an approach for faster acceptance, which would be decisive for the future involvement of stakeholders and the success of the landing obligation.

There are three issues that need to be addressed. First, the methods for industry self-sampling must be structured in a way that provides sufficiently solid data on the effect of the new or modified gear in an efficient manner for the fishers. Second, it must be evaluated whether the industry-collected self-sampling data show the same trends as those observed in the scientific trials. Third, it is necessary to clarify the legislative procedures involved in gear acceptance, in order to define how and whether it is possible to simplify and shorten the approval process once the relevant documentation is obtained. One aspect of this includes the possibilities for conditional acceptance under different condition than today. An example could be preliminary approval at a national level before being evaluated and subsequently approved at regional and EU level.

5 Is such "fast tracking of approval" possible with the new regulation under way?

Following the CFP reform of 2013 and the recognised problems of the current technical regulation, the EU Commission in March 2016 launched a proposal for a new technical regulation of the EU fisheries [7]. The proposal highlights the issues with the current technical regulation and presents three alternative options which can help alleviate these. Below we discuss these, especially the option preferred by the EU 
Commission, and how the methods developed in the FastTrack project can help facilitate the regionalised and flexible approach put forward in the proposal.

\subsection{The new draft proposal}

Three options are put forward in the proposal for a new technical regulation of the EU fisheries [7], which aim to address the shortcomings of the current technical measures regulation by i) introducing greater flexibility in the management framework by facilitating regionalised approaches, ii) increasing the involvement of key stakeholders in the decision making process, and iii) simplifying the current rules.

The most radical model offers the highest flexibility for the fisheries: Complete elimination of the existing rules, and full implementation of catch quota management. The proposal rejects this approach primarily for two reasons. The main reason is the difficulty to fully monitor the fishing activities, and thus the significant risk of fishers still discarding catches at sea without being detected. Another concern is the lack of control of broader ecosystem effects under a free choice of gear.

The least radical model is a consolidation of the current regulation, maintaining the common rules. The current measures would be split between European and regional regulations, a distinction that already exists to some extent in the current regulation. Regional groups can include derogations from these measures in discard plans and multiannual plans.

Between these two models is the preferred model, a "Framework approach with baselines". This model links the technical regulation to the regional multi-annual management plans, designed by the high-level regional groups of fisheries directors as described in article 18 in the 2013 CFP. The baselines consist of the regional specific elements of the current technical regulation. This means, that the present detailed regulation will be continued as common rules and regionally specific measures. The latter might change as alternative measures are implemented in the regional management plans.

At present, the draft proposal is still in the co-decision process where the proposal from the Commission has been discussed by the EU-Parliament and is now up for discussion with the Council of Ministers [27]. The process of the "Framework approach with baselines" is elaborated below, but central elements of this already appear to be the new practice as a part of the regionalisation of management plans, following the 2013 CFP.

\subsection{The acceptance protocol}

In the context of the regionalised "Framework approach with baselines" and the regional management plans, the political process for changes would be less bureaucratic than the present system. The EUcommission were given permission, through a delegated act, to approve joint recommendations from the regional groups [1]. Therefore, the co-decision process between the Commission, Parliament and Council has been removed as a part of the future acceptance process. The management plans are supposed to be "adopted in consultation with Advisory Councils, operators in the fishing industry, scientists and other stakeholders having an interest in fisheries management" $[1,(24)]$. The unknown factor thus is how the process of creating and changing multi-annual management plans will be. The processes within the regional groups have not been very transparent [28], however the regional groups and their procedures are still 
under development and the outcomes in the joint recommendation are available, e.g. at the home pages of the regional advisory councils (bsac.dk and nsac.org).

The technical regulation, including the regulation of gears, will be an integrated part of the multi-annual management plans. The management plans are supposed to be evaluated every fifth year (e.g. the proposal of North Sea multi-annual management plan [29]) and the multi-annual management plan for the Baltic Sea [30]. The member states may submit joint recommendations every twelve months, and "when deemed necessary" ([30], art 2, §2.) These yearly joint recommendations might include proposals of new innovative gear or gear variations to be included in the management plan. Thus, there seems to be an opening for an annual evaluation of new gears, if it can contribute to the overall goal of the management plan. As a perspective, one could discuss whether it is possible to have a more flexible national implementation of new or modified gears prior to them being presented as part of the yearly joint recommendations.

\subsection{The evaluation protocol}

The flexibility of the proposed technical regulation partly depends on how the need for scientific documentation is interpreted and therefore, the associated cost and time outlay. The proposal text requires "best scientific advice", though it does not specify the evaluation method (e.g. population dependent versus population independent).

As mentioned in section 3.2, the evaluation procedure by STECF far has not been based on a fully formalised approach method. Work is however on the way to establish such an evaluation framework, based on the experience accumulated [31]. Other low-cost methods for structured documentation of the effect of a new gear could be accepted, but this requires acceptance by the scientific community, as STECF will maintain the central role in assessing a gear's effect in the proposal e.g. in article 24 of the proposal for new technical measures [7]:

\section{Innovative fishing gears}

1. When Member States submit joint recommendations in accordance with Article 19 to allow for the use or extend the use of innovative fishing gears including the pulse trawl as described in Part $E$ of Annex $V$ within a specific sea basin, they shall provide an assessment of the likely impacts of using such gears on the targeted species and on sensitive species and habitats.

2. Those assessments shall be evaluated by the STECF.

3. The use of innovative fishing gears shall not be permitted where those assessments indicate that their use will lead to negative impacts on sensitive habitats and non-target species.

\section{Discussion and conclusion}

Here we show that there are opportunities for a faster and more inclusive development and testing of fishing gears, and that the proposed technical measures regulation provides opportunities for a faster acceptance of new and/or modified gears in the regulation. This is illustrated in figure 2 , where the changed structure of gear development, documentation and validation is compared to the current structure illustrated in figure 1. 
Figure 2: Flow diagram describing the possible main elements in the process of identifying, developing, testing, documenting and evaluation of new selective gear leading to political implementation in multiannual management plans under the proposed technical regulation and a "FastTrack-like" development model.
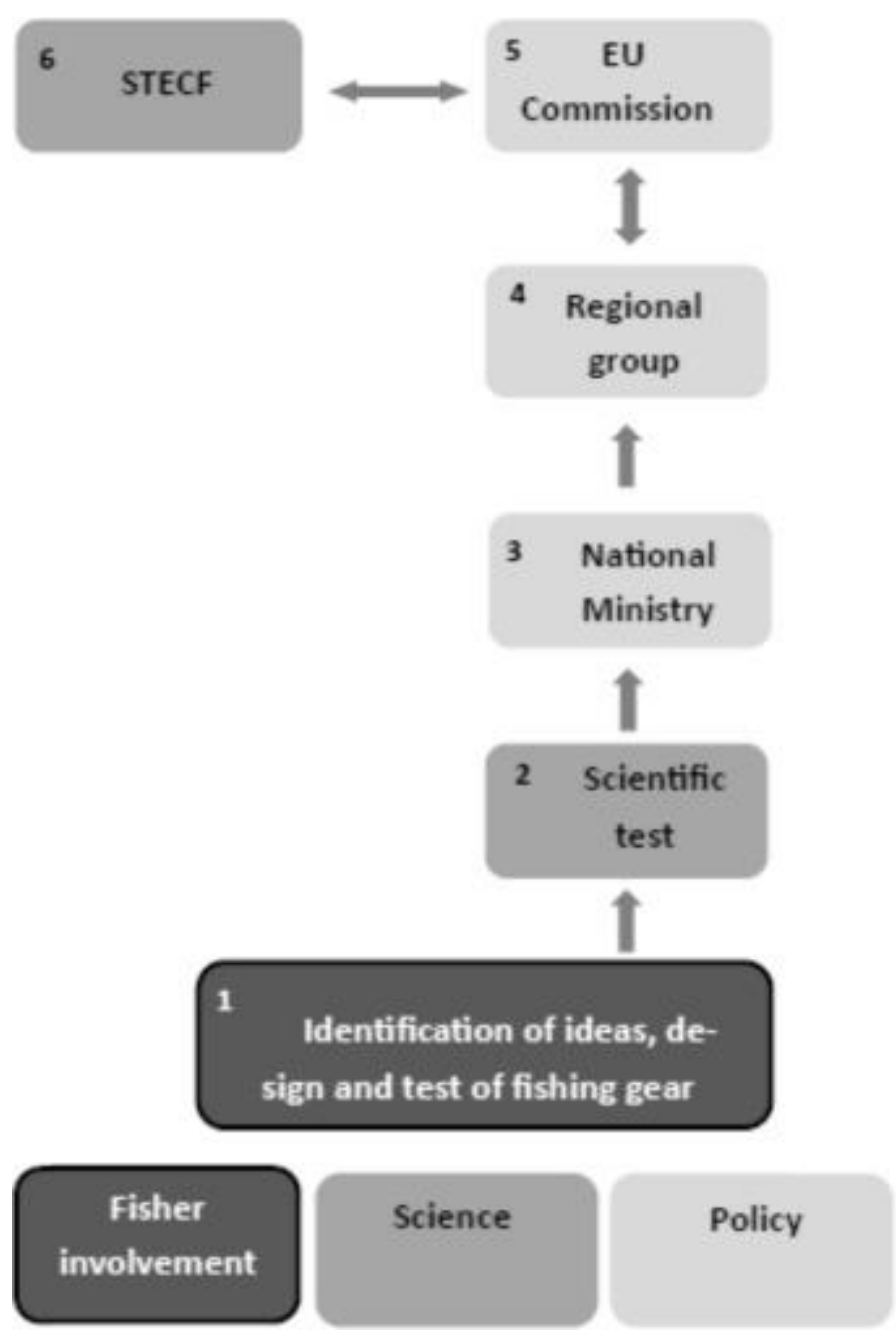

The development and testing of new and/or modified gear designs (1) is not mentioned in the proposed technical measures regulation. Thus, there remains a need for scientists to develop adequate, robust and cost-efficient protocols for data collection and documentation, which involve the industry. Such protocols are being trialled in a number of countries [32]. Based on the FastTrack project experiences, we suggest to involve the industry in the development, testing and documentation phases before carrying out a thorough scientific trial. The incorporation of stakeholders in the development, testing and documentation phases increases the amount of potential solutions available to address the issues arising. By opening for a range fisher initiated trials in parallel, the most selective designs can, in a short time, be identified and chosen for scientific tests. By having funding available a priori, the process of gear development and testing can start immediately after the panel's acceptance. This avoids time-consuming processes of applying for funding for 
the specific project, which fast tracks the process further, while the risk of loss of engagement from the initiating fisher is reduced.

Some elements of the process of identifying problems and solutions to political implementation are the same as in the former structure. Scientific tests at national level (2) and the European scientific assessment in STECF (5) are still central in the proposed technical measure regulation to ensure the high level of scientific documentation for the sustainability (generally selectivity) of the proposed gear designs. Furthermore the national ministries (3) still are responsible for carry the results of scientific tests into the further political handling, now at first in the regional groups.

The proposed technical measures regulation mainly addresses the bottlenecks linked to the process of assessment and acceptance of new gear designs. Two central elements are changed; 1 ) the time and effort spent on the political decision process is reduced as the responsibility to accept the use of a specific gear is now delegated to the EU Commission (6), previously a matter of the co-decision process between Commission, EU Parliament and Council of Ministers, 2) technical regulation is integrated in the regional multi-annual management plans.

The regionalised procedure is that the national ministries carry documented proposals of a new gear design in the relevant regional group (4) to be discussed and potentially implemented in the regional multi-annual management plans. These plans are formulated as joint recommendations, which are then accepted (or rejected) by the Commission (6). The management plans are five-year plans, which can be revised every year, and even on an ad hoc basis. The opportunity of running adjustments opens the possibility for a faster route in the political processing from documentation of a new gear design to acceptance.

Additionally, providing an opportunity to grant temporary and conditioned acceptance at a national level on the basis of cooperative industry-science documentation would facilitate further flexibility within the technical measure regulations. This would make it possible to address and resolve issues on an ad hoc basis (e.g. the implementation of a new gear to avoid a species choking a fishery) prior to receiving a more formal evaluation as part of the yearly joint recommendations. Furthermore, it would constitute a decisive step towards increased stakeholder involvement within management while also increasing ownership and willingness to engage in selectivity improvements from the fishing industry. This is something, which could be facilitated through the regional groups since regionalisation was highlighted as one of the key points in the proposed technical measures regulation.

The proposal for a new technical regulation with fast track processes involving the industry in gear development opens up for a potentially more flexible and proportionate process for the development, testing, validation and acceptance of new gear designs. To achieve this, and address the known shortcomings of the current technical regulation, it is important that a number of steps and protocols are clarified and formalised. The acceptance of new gears must be embedded in the regional management plans. Collaborative industry-science partnerships must be established to achieve the needed flexibility and involvement of stakeholders as highlighted in the proposed technical measure regulation. Ensuring that there is already financing available to support the development process can speed up the process and the fisher involvement. The collaboration also has the potential to reduce the costs associated with the development and testing of new gear designs, and time and fisher engagement lost in long application 
processes. Fast tracking the development and acceptance phases would constitute decisive progress towards achieving the objectives of the Common Fishery Policy.

\section{Acknowledgements}

This work has received funding from the European Maritime and Fisheries Fund (EMFF) and the Danish Ministry of Environment and Food of Denmark in the FastTrack project - Sustainable, cost effective and responsive gear solutions under the landing obligation, as well as from the from the Horizon 2020 Programme under grant agreement DiscardLess number 633680. This support is gratefully acknowledged.

\section{References:}

[1] EC (2013). Regulation (EU) No 1380/2013 of the European Parliament and of the Council of 11 December 2013 on the Common Fisheries Policy, amending Council Regulations (EC) No 1954/2003 and (EC) No 1224/2009 and repealing Council Regulations (EC) No 2371/ 2002 and, Official Journal of the European Union L 354/22 28.12.2013--28.12.2013 (2013).

[2] Krag L. A. et al (2016). Escape panels in trawls-a consistent management tool? Aquatic Living Resources, 29(3), 306. doi.org/10.1051/alr/2016028

[3] EC (2015). COUNCIL REGULATION (EC) No 850/98 of 30 March 1998 - CONSOLIDATED - for the conservation of fishery resources through technical measures for the protection of juveniles of marine organisms Euro-lex. ELI: http://data.europa.eu/eli/reg/1998/850/2015-06-01.

[4] Squires, D., \& Kirkley, J. (1999). Skipper skill and panel data in fishing industries. Canadian Journal of Fisheries and Aquatic Sciences, 56(11), 2011-2018. http://doi.org/10.1139/f99-135

[5] O’Keefe, C. E., Cadrin, S. X., \& Stokesbury, K. D. E. (2014). Evaluating effectiveness of time/area closures, quotas/caps, and fleet communications to reduce fisheries bycatch. ICES Journal of Marine Science: Journal Du Conseil, 71(5), 1286-1297. http://doi.org/10.1093/icesjms/fst063

[6] Eliasen, S. Q., \& Bichel, N. (2016). Fishers sharing real-time information about "bad" fishing locations. A tool for quota optimisation under a regime of landing obligations. Marine Policy, 64, 16-23. DOI: 10.1016/j.marpol.2015.11.007

[7] EC. (2016). Proposal for a Regulation of the European Parliament and of the Council on the conservation of fishery resources and the protection of marine ecosystems through technical measures, amending Council Regulations (EC) No 1967/2006, (EC) No 1098/2007, (EC) No, Pub. L. No. COM(2016) 134 final (2016).

[8] EC (2016). Annexes to the Proposal for a regulation of the European Parliament and of the Council on the conservation of fishery resources and the protection of marine ecosystems through technical measures, Pub. L. No. COM(2016) 134 final (2016). 
[9] Melli, V. et. al. (2017). FLEXSELECT: counter-herding device to reduce bycatch in crustacean trawl fisheries. Canadian Journal of Fisheries and Aquatic Sciences, 00: 1-11 (0000) dx.doi.org/10.1139/cjfas2017-0226

[10] EC (1998). COUNCIL REGULATION (EC) No 850/98 of 30 March 1998 for the conservation of fishery resources through technical measures for the protection of juveniles of marine organisms. Official Journal of the European Communities L 125, 27.4.1998, p. 1

[11] Eliasen et. al. (2015) Udvikling af fælles vidensplatform for screening af fiskerideer til nye redskaber (development of knowledgeplatform for screening of fisher initiated new gear) in Frandsen et ai 2015. Sustainble development of the Nephophs fishery in the Kattegat-Skagerak region. DTU-Aqua report no. 298-2015

[12] European Parliament (2018). About Parliament Legislative powers. Found March 2018: http://www.europarl.europa.eu/aboutparliament/en/20150201PVL00004/Legislative-powers

[13] STECF (2011) Scientific, Technical and Economic Committee for Fisheries (STECF) - 38th Plenary Meeting Report (PLEN-11-03). 2011. Publications Office of the European Union, Luxembourg, EUR 25033 EN, JRC 67714, 104 pp. doi:10.2788/98352

[14] STECF (2012) Scientific, Technical and Economic Committee for Fisheries (STECF) - 39th Plenary Meeting Report (PLEN-12-01). 2012. Publications Office of the European Union, Luxembourg, EUR 25303 EN, JRC 70759, 112 pp. doi:10.2788/23845

[15] STECF (2012) Scientific, Technical and Economic Committee for Fisheries (STECF) - 40th Plenary Meeting Report (PLEN-12-02). 2012. Publications Office of the European Union, Luxembourg, EUR 25411 EN, JRC 73093, 126 pp. doi:10.2788/38386

[16] STECF (2012) Scientific, Technical and Economic Committee for Fisheries (STECF) - 41th Plenary Meeting Report (PLEN-12-03). 2012. Publications Office of the European Union, Luxembourg, EUR 27220 EN, JRC 76701, 115 pp. doi:10.2788/63585

[17] STECF (2013) Scientific, Technical and Economic Committee for Fisheries (STECF) - 44th Plenary Meeting Report (PLEN-13-03). 2013. Publications Office of the European Union, Luxembourg, EUR 25579 EN, JRC 86096, 124 pp. Printed in Italy doi:10.2788/38198

[18] STECF (2014) Scientific, Technical and Economic Committee for Fisheries (STECF) - 45th Plenary Meeting Report (PLEN-14-01). 2014. Publications Office of the European Union, Luxembourg, EUR 26616 EN, JRC 89783, 86 pp. Printed in Italy. doi:10.2788/61144

[19] STECF (2014) Scientific, Technical and Economic Committee for Fisheries (STECF) - 46th Plenary Meeting Report (PLEN-14-02). 2014. Publications Office of the European Union, Luxembourg, EUR 26810 EN, JRC 91540, 117 pp. Printed in Italy. doi:10.2788/11931X

[20] STECF (2014) Scientific, Technical and Economic Committee for Fisheries (STECF) - 47th Plenary Meeting Report (PLEN-14-03). 2014. Publications Office of the European Union, Luxembourg, EUR 26944 EN, JRC 93037, 138 pp. Printed in Italy. doi:10.2788/43328 
[21] STECF (2015) Scientific, Technical and Economic Committee for Fisheries (STECF) - 48th Plenary Meeting Report (PLEN-15-01). 2015. Publications Office of the European Union, Luxembourg, EUR 27220 EN, JRC 95802, 75 pp. doi:10.2788/40738

[22] MRAG et al. (2014). A study in support of the development of a new Technical conservation measures framework within a reformed CFP. Lot 2: retrospective and prospective evaluation on the Common fisheries policy, excluding its international Dimension. Brussels. 265pp

[23] STECF 2013. Scientific, Technical and Economic Committee for Fisheries - Different Principles for defining selectivity under the future TM regulation (STECF-13-04). 2013. Publications Office of the European Union, Luxembourg, EUR 25973 EN, JRC 81584, 38 pp. doi:10.2788/90188

[24] EC. Consultation: Development of a new framework for technical measures in the reformed CFP, found March 2018 at: https://ec.europa.eu/info/consultations/technical-measures-reformed-common-fisheriespolicy_en\#documents

[25] Krag et al. (2014). Inferring fish escape behaviour in trawls based on catch comparison data: Model development and evaluation based on data from Skagerrak, Denmark. PloS one, 9(2): e88819, https://doi.org/10.1371/journal.pone.0088819.

[26] Feekings J. et al (2017). Cruise report. R 218 Judith Bechmann. Testing a modified T90 codend in the Baltic cod trawl fishery and the effect of different design parameters on the selectivity of cod. National Institute of Aquatic Resources, Hirtshals, Denmark. August 2017

[27] Mato G. 2018. Legislative train schedule. Fisheries. Fisheries Technical Measures, as of feb 202018 , found 01032018 at: http://www.europarl.europa.eu/legislative-train/theme-fisheries/file-fisheriestechnical-measures.

[28] Eliasen, S. Q. et al (2015). Decentralising: The implementation of regionalisation and co-management under the post-2013 Common Fisheries Policy. Marine Policy, 62, 224-232.

http://doi.org/10.1016/i.marpol.2015.09.022

[29] EC (2016). Proposal for a Regulation of the European Parliament and of the Council on establishing a multi-annual plan for demersal stocks in the North Sea and the fisheries exploiting those stocks and repealing Council Regulation (EC) 676/2007 and Council.

[30] EC (2016). Regulation (EU) 2016/1139 of the European Parliament and of the Council of 6 July 2016 establishing a multiannual plan for the stocks of cod, herring and sprat in the Baltic Sea and the fisheries exploiting those stocks, amending Council Regulation (EC) No 2187/2005 and repealing Council Regulation (EC) No 1098/2007

[31] STECF 2017 Scientific, Technical and Economic Committee for Fisheries (STECF) - Technical measures (STECF-17-02); Publications Office of the European Union, Luxembourg; EUR 28359 EN; doi:10.2760/51636

[32] Feekings, J. et al (2018) An evaluation of European initiatives established to encourage industry-led development of selective fishing gears. Unpublished article 